Susanna Öhman, Anna Olofsson, Katarina Giritli Nygren

\title{
A METHODOLOGICAL STRATEGY FOR EXPLORING INTERSECTING INEQUALITIES: AN EXAMPLE FROM SWEDEN
}

The article explores the complex patterns of inequality in Sweden from an intersectional standpoint by developing a methodological strategy using data from quantitative national survey material. Intersectionality stands in contrast to the inductive and hypothesis-testing approaches, which tend to reproduce categories as having an essential and stable meaning. It is generally acknowledged that quantitative approaches to intersectionality are rare or in development. Quantitative analyses tend to disregard some of the theoretical cornerstones of intersectionality: in particular, the relational and fluid character of categories. This may be why intersectionality researchers tend to reject quantitative approaches altogether. To address this dilemma, Multiple Correspondence Analysis (MCA) is applied as a means of linking objective structures to subjective experiences, and it is argued that this methodology is well suited to detecting and capturing social spaces of privilege and oppression. The result shows that this kind of quantitative approach to intersectional analysis can facilitate the exploration of inequalities and positions of privilege across populations and globally at particular times, as well as contributing to ontological and epistemological perspectives on intersectionality. By exploring what the category is said to describe and how these parts relate to other subcategories, especially about time and place settings and their intersections, we were able to identify relationships between structures of oppression and subjective experiences at a particular time and in a particular place, which is important in understanding both inequalities and positions of privilege. These analyses not only illuminate the hegemonic structures of power that create

Susanna Öhman - PhD, Associate professor in Sociology, Risk and Crisis Research Centre, Mid Sweden University, Sweden. Email: susanna.ohman@miun.se

Anna Olofsson - PhD, Professor in Sociology, Risk and Crisis Research Centre, Mid Sweden University, Sweden. Email: anna.olofsson@miun.se

Katarina Giritli Nygren - PhD, Associate professor in Sociology, Forum for Gender Studies, Mid Sweden University, Sweden. Email: Katarina.giritli-nygren@miun.se 
subordinated and privileged positions but also help us to theorize the nonlinear and stochastic relations between and within these positions. This methodological advance also has important implications for social policy.

Keywords: intersectionality, Multiple Correspondence Analysis (MCA), Quantitative intersectional analysis

DOI: 10.17323/727-0634-2018-16-3-501-516

There have been numerous studies of inequality in Sweden, not only in terms of gender but also in relation to ethnicity, class, sexuality and their intersections (Martinsson et al. 2016). It is especially pertinent to study inequality in Sweden, as the country has a history of equality-driven social policies. However, the Swedish model of social welfare and security has undergone fundamental change since the early 1990s, with welfare cuts along neoliberal lines and the introduction of a new type of public governance (Larsson et al. 2012). It is as yet unclear whether these changes are leading to new inequalities. At the same time, despite this government restructuring, the welfare state continues to maintain responsibility for redistributing symbolic and material resources, and Sweden still has relatively few income inequality, health or social problems.

Although we know that inequalities related to gender, ethnicity and class persist, current modes of governance tend to neglect the complexities of present inequalities when using a 'neutral' approach to social policy (Daly 2011; Lewis 2005). Public discourses and practices around risk often employ overgeneralised notions of 'at risk' groups and the 'average' life course, stereotyping people such as single mothers, young people from a foreign background or elderly people with low education, and, as a result, create new forms of inequality and disadvantage (Giritli Nygren et al. 2016).

Sociological investigation has traditionally highlighted the gendered, racialized or class-structured nature of welfare policy and reform, in terms of both process and outcome. The precise aspects of race, gender and class that actually contribute to the understanding of welfare policy outcomes are not explored to the same extent. By using intersectionality as a frame to highlight the complexities of oppression, analysis of welfare policy can move beyond the prediction of human vulnerability and behaviours. One way of capturing and understanding the complex interplay between gender and other social differentiations in societies such as Sweden is by applying the theoretical framework of intersectionality. In recent years, the intersectional approach has achieved a major breakthrough in the sociology of gender and inequalities (e.g. Walby et al. 2012; Choo, Ferree 2010), prompting a number of theoretical and conceptual discussions about how gender might be understood and analysed in combination with other categories.

We view the growing focus on intersectionality as a positive trend that potentially captures the complex interplay between gender and other social dif- 
ferentiations in contemporary, multicultural societies. The associated methodological issues have been widely discussed (Cho et al. 2013; Harnois 2013) but still tend to follow divides based on disciplinary traditions rather than on theoretical assumptions. One challenge relates to the combination of intersectionality as a theoretical approach and the positivistic assumptions underlying quantitative methods. Clearly, quantitative approaches have limitations in terms of the levels of complexity that can be taken into account, but there is strategic value in finding ways of using statistics and quantitative data to generalize results. Like many earlier researchers, we believe that the insights offered by intersectionality are important for quantitative research, on the grounds that surveys are of value when they incorporate the tools necessary to operationalize intersections of different categories and differing complexity (Berg 2010; Harnois 2013; Sprauge 2005). Investigation of these intersections makes it possible to establish more sophisticated linkages between oppressive structures and subjective experiences and preferences, and to better comprehend the potential material consequences of, for example, class, gender and racial imagery (e.g. Harnois, Ifatunji 2011; Penner, Saperstein 2013). While theoretical principles (e.g. Lykke 2011; Lutz et al. 2011) and qualitative methodologies (e.g. Bowleg 2008; Christensen, Jensen 2012) have already been extensively discussed, there has been less debate about less attention has been devoted to quantitative intersectional methodology and analysis (McCall 2005).

That being so, the objective here is to explore the complex patterns of inequality in Sweden from an intersectional standpoint, based on national survey material. The use of more explorative empirical methods avoids undermining any challenge to the original cornerstones of the intersectional approach. To that end, before presenting the empirical case, we will situate our arguments within the ongoing discussion of intersectional methods, relating primarily to researchers who have exhibited similar ambitions rather than to the originators of intersectionality.

\section{Intersectional methods: contestations and controversies}

Many scholars have demonstrated that processes of inequality may work in different ways for people living within different intersections of gender, race and class, particularly under the umbrella of intersectional analysis (e.g. Walby et al. 2012; Choo, Ferree 2010). The concept of intersectionality was first used by Kimberlé Crenshaw (1989) to account for the ways in which race, gender and class intersect to position black women, with particular reference to the law. From the outset, intersectionality was strongly invested in the intersection of race and gender, with black feminism acting as the key foundation (see for example Crenshaw 1989; Collins 2000). In discussing intersectionality as a theoretical-methodological tool, three aspects are noteworthy: the inclusion of the perspectives of multiply marginalized people; the analytical shift 
away from an additive model of social categories as constructing degrees of oppression to the interactions of these categories; and a willingness to see multiple categories, practices and institutions as overlapping (Choo, Ferree 2010; cf. McCall 2005). These interlocking systems of social stratification create a complex matrix of privilege and subordination, in which the positioning of the subject influences individual worldviews and life chances in ways that differ from the impact of any single form of stratification (Collins 2000).

Intersectionality essentially raises the fundamental methodological question of how to analyse such mutually constitutive processes. Several authors have discussed these complexities in terms of the status of the social categories. Leslie McCall (2005) offers one of the most nuanced discussions of this topic from a sociological perspective, emphasising that different approaches to social categories produce different types of knowledge (for similar but differing typologies, see Choo, Ferree 2010; Hancock 2007). McCall (2005) describes three approaches on the basis of how categories and categorizations are handled: anti-categorical complexity, intra-categorical complexity and inter-categorical complexity.

The first two of these deconstruct analytical categories and question the use of quantifiable variables, as categories are seen as a reductionist means of understanding the complexity of intersecting power relations. Most intersectional research adopts one of these two approaches; relatively few studies employ an inter-categorical approach to complexity, which recognizes the existence of relationships of inequality between social groups and takes the relationships as the point of departure for analysis, studying complexity and variation in the interrelations between different categories of inequality (e.g. McCall 2005). Focusing on relationships between categories or social groups, the meaning of the combination of categories is given at any particular time, and inequality is not presupposed but is treated as a hypothesis.

Lisa Bowleg (2008) argued that the challenge of quantitative intersectional analysis relates to its capacity to address meaningful constructs such as stress, prejudice and discrimination rather than on demographic issues alone. For present purposes, our point of departure is that, just as qualitative methods are needed to achieve an understanding of individual experiences, life trajectories and discrimination, quantitative methods are needed to identify possible structures of inequality and any effects of this inequality at a societal (or even global) level (Harnois 2009; McCall 2005; Scott 2010).

As we have seen, a number of challenges must be resolved in order to be able to use quantitative methods for intersectional analysis. In our view, the most important challenges for exploring intersecting inequalities relate to categorizations and stability. We have already shown that almost all conceptualizations of intersectionality touch on categorizations, or on the avoidance of categorization, and whether it is appropriate to apply additive or multiplicative methods in the analyses. Less visible but nevertheless intimately connected is the question of the stability or fluidity of categories or positions (Walby et al. 2012). 
To address these challenges, Sylvia Walby et al. (2012) argued the need for greater depth in the ontology of intersecting inequalities, as well as greater sophistication in the analysis of how these sets (or systems) of social relations affect each other, by acknowledging the historically constructed nature of social inequalities and their sedimentation in social institutions (cf. Choo, Ferree 2010). By viewing 'categories' as historically institutionalized positions interlocked through social relations, the dichotomy of stable/fluid and the 'dichotomy of dichotomies' can be overcome, as all categories are positioned and therefore acquire meaning in relation to each other (Nakano Glenn 2002: 13; cf. McCall 2005).

To meet these challenges, we need a method that explores the intersections of privilege and disadvantage rather than confirming predefined categories. By viewing gender, race, class and so on as relational time-space-dependent positions - that is, not static but dependent on each other and on time and context - it becomes possible to translate the intersectional assumptions of multiple belongings into quantitative measurements (Walby et al. 2012, cf. McCall 2005). As Walby et al. (2012) argued, stability is achieved through institutionalization of structures of privilege and oppression, bringing relative stability to the experience of social inequality. As social institutions change, so too does the environment within which specific sets of social inequalities are negotiated and handled.

On the basis of the above arguments, geometric methods in general and multiple correspondence analysis (MCA) in particular seem appropriate. MCA creates models from the data rather than the other way round; it requires no numerical data and assumes no particular distribution, and calculations are not based on means. However, contingency tables are used to create spaces or multidimensional plots of individuals and their characteristics (Le Roux, Rouanet 2010). These spaces of inequalities are generated by the relations between variables; depending on which variables are included, it is possible to identify patterns of oppression, privilege and combinations of the two. As we have shown, many feminist inequality studies that argue the need to quantify intersectional relations of power are informed by McCall's (2005) conception of inter-categorical complexity, taking relationships between social categories as the point of departure. Here, we attempt to take this a little further by opening the black boxes of gender, race and class, which often remain closed in such inter-categorical analyses, by exploring what the category is said to describe and how these parts relate to other sub-categories, so enabling the necessary temporal definition of positions in social hierarchies based on gender, race and class.

\section{Data and method}

To measure this relational approach to inequality, we employ the explorative method of MCA (Le Roux, Rouanet 2010), which makes it possible to link objective structures to subjective experiences. Some scholars have previously suggested that this methodological approach (although not necessarily 
the particular statistical method) is well suited to intersectional analysis (Fowler 2003; Tatli, Özbilgin 2012). However, few studies to date have applied this method in empirical investigations. By linking positions to resources and experiences, MCA enables the extraction of the core dimensions of these relationships (Lee et al. 2012) and the inclusion of assemblages of positions into the social spaces these dimensions create.

MCA facilitates the analysis of relationships among several categorical variables, using standard correspondence analysis on a matrix whose entries are 0 or 1 (Abdi, Valentin 2007). In other words, rather than identifying dependent and independent variables, MCA utilizes the associations between variables by representing their relationships as points in a multidimensional space. MCA produces dimensions that individually explain some of the variance in the variable matrix; these are also visualized as two-dimensional 'maps', 'spaces' or 'fields', in which the dimension that explains most variance is combined with the X-number of additional dimensions (Veenstra 2011). To make interpretation easier, the number of dimensions is commonly limited. For the present purposes, the identified dimensions will be referred to here as 'core dimensions'.

To explore the complexity of inequality relations in Sweden, we used data from the Survey of Risk and Society (SRS), a national survey conducted during the autumn of 2011. The dataset used in the analyses is composed of two representative samples of the Swedish population between the ages of 16 and 75: a random national sample of all inhabitants of Sweden $(n=2500$; response rate $41 \%$ ) and a random sample of people living in three districts of Stockholm, Gothenburg and Malmö $(n=1000$; response rate $25 \%)$. In total, 1,078 people completed the questionnaire. The purpose of the second sample was to increase the number of people from foreign backgrounds in the dataset. Because of language problems and incompleteness or inaccuracy of address, the response rate among people from foreign backgrounds was expected to be low.

The SRS included a total of 280 questions, drawing on the previous SRS of 2005 and 2008, as well as other earlier studies (e.g. Olofsson, Öhman 2007). The range of questions encompassed worldview, political orientation, happiness, income, social support, experience of discrimination, trust, risk perception and experience of certain crises, as well as collecting extensive socioeconomic information about respondents. For the intersectional analyses, we formulated questions that captured information about the respondent's position in the matrix of domination.

We analysed the positions of gender, ethnicity and social class by relating them to each other and to various resources and experiences. Questions related to resources included such topics as dwelling, education, social support (i.e. help with economic, emotional and practical issues), happiness, marital status, social status and trust in others, as well as questions about experiences such as discrimination (on grounds of ethnicity, gender and religion) and violence. Gender was recorded as woman or man; ethnicity was based on place of birth 
of the respondent or the respondent's mother or/and father, and social class was based on income and labour market position (i.e. 'Class'; see Figures 1 and 2). This somewhat unorthodox approach, combining socio-demographic variables with attitudes, was used to map complex patterns of inequality. We argue that, within the framework of intersectionality, it is important to include both socio-demographics and constructs such as discrimination and trust (Bowleg 2008) in identifying spaces of inequality.

Table 1

Construction of assemblages

\begin{tabular}{|c|c|c|c|c|}
\hline Gender & Ethnicity & Class/Income & $\begin{array}{l}\text { Assemblage } \\
\text { Acronyms }\end{array}$ & $N$ \\
\hline Women (W) & Sweden (S) & Low Income (LI) & W S LI & 109 \\
\hline Women (W) & Sweden (S) & Middle Income (MI) & W S MI & 263 \\
\hline Women $(\mathrm{W})$ & Sweden (S) & High Income (HI) & W S HI & 66 \\
\hline $\operatorname{Men}(\mathrm{M})$ & Sweden (S) & Low Income (LI) & M S LI & 56 \\
\hline $\operatorname{Men}(\mathrm{M})$ & Sweden (S) & Middle Income (MI) & M S MI & 205 \\
\hline $\operatorname{Men}(\mathrm{M})$ & Sweden (S) & High Income (HI) & M S HI & 106 \\
\hline Women (W) & Europe (E) & Low Income (LI) & W E LI & 10 \\
\hline Women $(\mathrm{W})$ & Europe (E) & Middle Income (MI) & W E MI & 34 \\
\hline Women (W) & Europe (E) & High Income (HI) & W E HI & 7 \\
\hline $\operatorname{Men}(\mathrm{M})$ & Europe (E) & Low Income (LI) & MELI & 7 \\
\hline $\operatorname{Men}(\mathrm{M})$ & Europe (E) & Middle Income (MI) & M E MI & 30 \\
\hline $\operatorname{Men}(\mathrm{M})$ & Europe (E) & High Income (HI) & M E HI & 9 \\
\hline Women (W) & $\begin{array}{l}\text { Africa, Asia, South } \\
\text { America (A) }\end{array}$ & Low Income (LI) & W A LI & 24 \\
\hline Women (W) & $\begin{array}{l}\text { Africa, Asia, South } \\
\text { America (A) }\end{array}$ & Middle Income (MI) & W A MI & 43 \\
\hline Women (W) & $\begin{array}{l}\text { Africa, Asia, South } \\
\text { America (A) }\end{array}$ & High Income (HI) & W A HI & 7 \\
\hline $\operatorname{Men}(\mathrm{M})$ & $\begin{array}{l}\text { Africa, Asia, South } \\
\text { America (A) }\end{array}$ & Low Income(LI) & M A LI & 21 \\
\hline $\operatorname{Men}(\mathrm{M})$ & $\begin{array}{l}\text { Africa, Asia, South } \\
\text { America (A) }\end{array}$ & Middle Income (MI) & M A MI & 36 \\
\hline $\operatorname{Men}(\mathrm{M})$ & $\begin{array}{l}\text { Africa, Asia, South } \\
\text { America (A) }\end{array}$ & High Income (HI) & M A HI & 10 \\
\hline
\end{tabular}

To deepen our understanding of how the core dimensions relate to intersectional positions in social space, examples of assemblages were constructed using positions of gender, ethnicity and class (see Table 1). Social class has been measured using two sets of variables (income and labour market position). 
Figure 1. Multiple Correspondence Analysis of core dimensions 1 and 2, Social status (horizontal axis) and Social and economic resources (vertical axis).
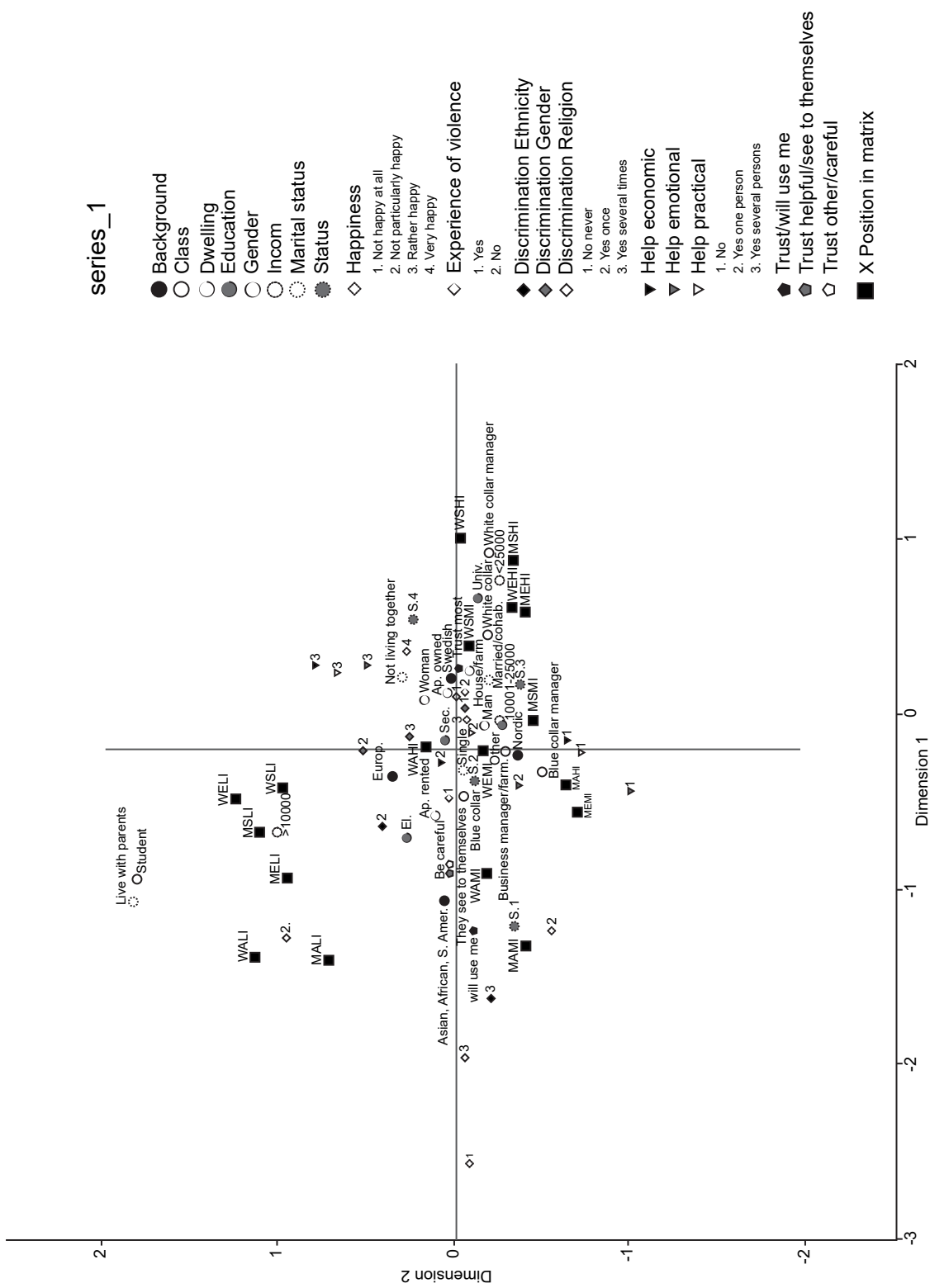
Figure 2. Multiple Correspondence Analysis of core dimensions 1 and 3, Social status (horizontal axis) and Social exclusion (vertical axis).

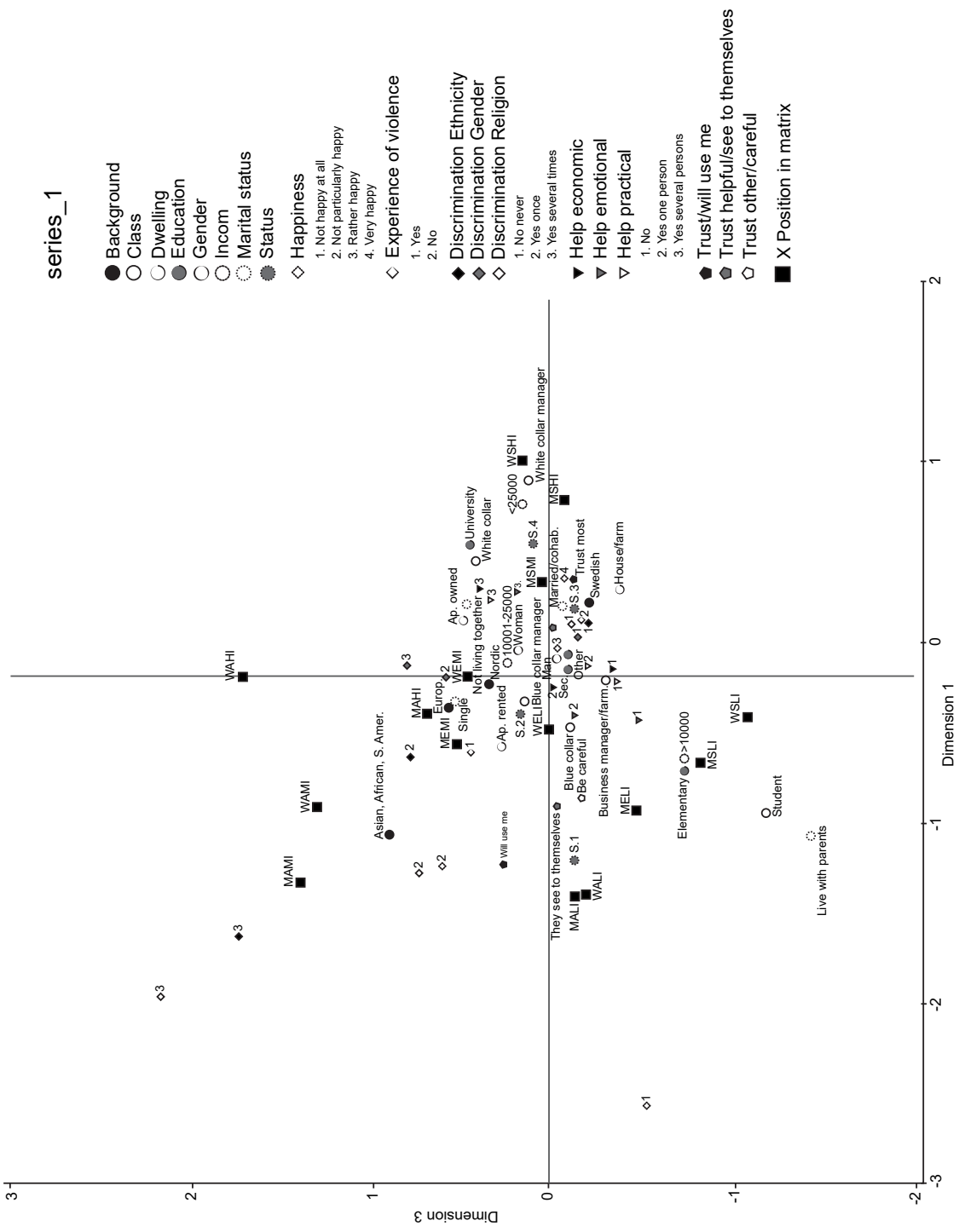


Here, the former was chosen for the intersectional analyses, principally because labour market position excludes those outside the labour market. These latter assemblages were entered in the analysis as 'inactive' or supplementary variables - that is, they were not used to compute the dimensions but were overlaid on the existent space (Veenstra 2009). Exploring the intersections of these positions might allow us to identify relationships between structures of oppression and subjective experiences at a particular time and in a particular place.

For the purposes of our analysis, rather than substituting missing values to avoid biased data, cases with missing data were excluded. This resulted in the exclusion of 194 out of 1094 cases from the analyses, which meant that 900 cases were analysed.

\section{Exploring intersecting inequality in Sweden}

This section presents the results of our analyses exploring individuals' positions within social relations, organising inequalities by gender, class and ethnicity. We began by identifying and interpreting the core dimensions, based on relationships among the positions, resources, and experiences reported by the respondents. The social spaces or matrixes of domination were then analysed intersectionally in terms of assemblages of positions.

Based on an evaluation of eigenvalues and explained variance, three core dimensions or axes of the MCA were further examined as the basis for analysis. These three dimensions accounted for approximately $40 \%$ of the variance among the variables used in the model and together created a three-dimensional space. As three-dimensional spaces are difficult to represent graphically on paper, the three core dimensions were pictured in two two-dimensional spaces (see Figures 1 and 2), showing the relations between positions, resources and experiences. In these two spaces, we overlaid assemblages of gender, ethnicity and class (see Table 1), which do not influence the formation of the space or dimension but are placed in the space on the basis of their relation to positions, resources and experiences. The three core dimensions and the two social spaces are further described and interpreted below.

\section{Formation of the social space}

The first dimension accounts for approximately $18 \%$ of the total variance of the social space (Figure 1) and has been labelled social 'status'. The left-hand side includes lack of trust in others, not being particularly happy with life and experience of violence and discrimination on grounds of religion and ethnicity, along with low self-rated status in society. The other end of the dimension is characterized by trust in others, high status and no experience of discrimination.

Although this intersectional analysis focuses on the intersections of gender, ethnicity and class, it is useful to first take a closer look at the three positions 
separately to differentiate between an explorative analysis of inequality based on the variables of gender, class and ethnicity and an intersectional analysis based on assemblages of positions (e.g. 'Swedish high-income male'). We find the gender positions of male and female close together, more or less in the middle of dimension 1, indicating small differences between these positions in terms of social status (or of any of the other dimensions, as we will see later). Ethnicity (or background) that includes being born or having parents born in Africa, Asia or South America is related to low social status; in contrast, a Swedish background confers high social status. High or middle income is also related to status; not surprisingly, the former is associated with high social status. Similarly, white-collar managers and workers have high social status while blue-collar workers are located closer to the middle. Clearly, then, ethnicity and class are discriminating factors in relation to status, but gender is not.

The second core dimension, represented by the vertical axis in Figure 1, accounts for approximately $12 \%$ of the total variance of the social space. We interpreted this dimension as representing level of social and economic 'resources'. The upper half of the graph includes social resources such as having several people to help with economic, emotional and practical matters, as in living with one's parents. At the other end of the dimension, social resources are scarce, with no-one to turn to for help and dwelling places such as own house or farm.

Gender positions are more or less insignificant in this dimension, although the female position is closer to the resourceful end of the dimension than the male position. While having a European background is associated with more social resources, originating from one of Sweden's neighbouring countries is associated with fewer resources. One interesting finding relates to income; while low income is relatively high on the dimension, middle and high income are lower, and the latter are more closely related to the social status dimension than to resources. This implies that possession of good economic resources is not related to having good social resources.

The second class indicator, labour market position, seems not to relate clearly to either kind of resource, although blue-collar managers are found to have few resources altogether. Overall, this dimension displays some intriguing characteristics, where the common ground is resources, but the two types (social and economic resources) occupy opposite positions on the dimension. While social resources (social networks) range from many to few on this dimension, economic resources such as income and more expensive housing go in the opposite direction, from low to high. This indicates an inverse or, to some extent, exchangeable relation between social and economic resources. It is important to note that very high incomes and white-collar jobs are unrelated to this dimension.

To view the third dimension, a second two-dimensional space must be drawn (see Figure 2). Here, dimension 1 ('status') is again displayed. However, the position of each observation differs from the first figure because, in this 
three-dimensional space, the positions change according to the angle of view. The third dimension accounts for approximately $11 \%$ of the total variance in the cloud of information, and we interpreted this as describing social 'exclusion'. The dimension is characterized by discrimination in terms of gender, ethnicity and religion, experience of violence and level of education. Experience of repeated discrimination due to religion and ethnicity lies at one end of the dimension with (to a lesser extent) experiences of gender discrimination and of violence. Of interest here is the finding that education also seems related to this dimension, but not in the way one might expect. While having a university degree is high on social exclusion (in a similar position as discrimination), lower education (e.g. elementary school) lies at the other end of the dimension. However, education is also related to the first core dimension (status); a university degree is associated with high status and elementary school education with lower status.

Turning to the positions of gender, ethnicity and class, we again find that gender positions do not relate to the dimension of exclusion. On the other hand, ethnicity seems important in understanding this dimension; while African, Asian or South American backgrounds are positioned as excluded, originating from Europe or a Nordic country is not. In particular, a Swedish background is associated with what can be interpreted as inclusion. Income is only marginally related to this dimension; low income is not positioned as excluded but relates only to elementary school education. Similarly, labour market position is more clearly related to status than to exclusion.

Looking at the overall picture, we find that background is related to exclusion but, like gender positions, exhibits no clear relation to status or resources. On the other hand, social class positions relate to status and, to some extent, to different resources.

\section{Intersecting inequalities within the social space}

Turning now to the central purpose of this paper, how to provide an intersectional analyses of the assemblages of gender, ethnicity and class/income, we can see how single positions of subordination and privilege transform into intersectional assemblages and to conditions of life and inequality. Returning to Figures 1 and 2, we find that low-income men and women with foreign backgrounds from outside Europe occupy similar positions in the social spaces; both have low status and limited economic resources and occupy a mid-range position in terms of exclusion. They experience more discrimination and violence than many others and see themselves as of low social status. They do not trust people as helpful or altruistic, and they have lower incomes but more social resources. While low-income men and women from Sweden and Europe occupy similar positions (low status and limited economic resources), they are not socially excluded. High-income Swedes and Europeans of both genders occupy 
similar positions on social status (high) and economic resources (high), but they differ in respect of social exclusion. European high earners of both genders are characterised by social exclusion, in contrast to Swedes with the same assemblage of positions. Interestingly, people with non-European backgrounds and good incomes are most excluded; even more than low-income men and women from outside Europe and Europeans with high and middle incomes.

These results clearly differ from our first interpretations of the different positions, resources and experiences, where, for example, the positions of women and men were very close. As another example, high- and middle-income earners with Asian, African and South American backgrounds are more socially excluded than low-income earners from the same regions. Whatever the reasons, the analyses of the assemblages of different intersecting positions reveal patterns of inequality and combinations of privilege and oppression that could not be identified by classical categorical analyses. MCA supports analysis of gender, ethnicity and class assemblages or other positions within social spaces defined by positions, resources and experiences. For example, it is possible to trace the privileged position of a high-income Swedish female and to contrast it with the subordinate positions of, for instance, a high-income female from outside Europe in terms of both status and exclusion. Had we looked at the single positions of class/income, gender and ethnicity, we might have concluded that gender positions are relatively unimportant in understanding social status and resources - which, as our intersectional analyses demonstrate, would be quite incorrect.

\section{Conclusion}

We argue here that the identification of quantitative and explorative methods for the study of inequality and the intersections of superior and subordinate various positions, and combinations of these, makes an important contribution to the study of inequality. Applying quantitative methods, existing sociological research on inequality tends to reproduce structures and positions in terms of variables such as gender, ethnicity and class, reinforcing the idea that these are stable and persistent over time and space and hindering any deeper understanding of the meaning of these positions and the dynamic relationships between them. Quantitative studies employing an intersectional perspective have also tended to avoid problematizing and developing new methods, instead adopting classical positivist assumptions and a hypothetical-deductive approach.

However, intersectionality raises important methodological questions, especially in relation to the possibility to utilize categories, frequencies and other such functions for quantitative analysis. Perhaps the most obvious and difficult challenge of quantitative intersectional analysis is that core attributes of intersectional analyses, such as multidimensionality, mutually constitutive relationships and interdependence, contradict the positivist assumptions inherent in 
most quantitative approaches and statistical analyses. Another significant difficulty relates to a position's stability or fluidity; while quantitative approaches require stability to enable statistical analysis, intersectional approaches stress the variation and changeability of positions (Hancock 2007; Walby et al. 2012). Other challenges relate to the availability of data; the fact that existing data are not developed to measure intersectional relationships, and that quantitative intersectional analyses commonly rely on demographic questions alone rather than on other meaningful constructs such as discrimination, trust and solidarity (Bowleg 2008).

We have shown that scholars in the field of intersectional studies differ in their view of both the opportunities and the need to apply quantitative methods in intersectional analyses. In this regard, we have tried to open up the black boxes of gender, race and class by exploring what the category is said to describe and how these parts relate to other sub-categories, especially time-place settings. Exploring the intersections of these positions allowed us to identify relationships between structures of oppression and subjective experiences at a particular time and in a particular place, which is important in understanding both inequalities and positions of privilege.

In this way, quantitative approaches to intersectional analysis facilitate an exploration of inequalities and positions of privilege across populations and globally at particular times, as well as contributing to ontological and epistemological perspectives on intersectionality. We are living in a time that assigns particular meanings to positions of gender, ethnicity and class that may change over time. These analyses not only illuminate the hegemonic structures of power that create subordinated and privileged positions but also help us to theorize the non-linear and stochastic relations between and within these positions. This methodological advance also has important implications for social policy. For example, for a non-European living in Sweden, our results show that a privileged class position may increase his or her exposure to discrimination, reminding us that it is not only anticipated inequalities that need to be addressed. Quantitative analyses of the kind reported here confirm that this is not only an individual experience but a structural problem within society.

\section{References}

Abdi H., Valentin D. (2007) Multiple Correspondence Analysis. N. Salkind (ed.) Encyclopedia of Measurement and Statistics. Thousand Oaks, CA: Sage: 651-657.

Berg J. A. (2010) Race, Class, Gender, and Social Space: Using an Intersectional Approach to Study Immigration Attitudes. Sociological Quarterly, 51 (2):278-302.

Bowleg L. (2008) When Black + Lesbian + Woman $\neq$ Black Lesbian Woman: The Methodological Challenges of Qualitative and Quantitative Intersectionality Research. Sex Roles, 59 (5-6):312-325. 
Cho S., Crenshaw K. W., McCall L. (2013) Toward a Field of Intersectionality Studies: Theory, Applications, and Praxis. Signs, 38 (4): 785-810.

Choo H. Y., Ferree M.M. (2010) Practicing Intersectionality in Sociological Research: A Critical Analysis of Inclusions, Interactions, and Institutions in the Study of Inequalities. Sociological Theory, 28 (2): 129-149.

Christensen A.- D., Jensen S. O. (2012) Doing Intersectional Analysis: Methodological Implications for Qualitative Research. NORA - Nordic Journal of Feminist and Gender Research, 20 (2): 109-125.

Collins P.H. (2000) Black Feminist Thought: Knowledge, Consciousness, and the Politics of Empowerment. New York: Routledge.

Crenshaw K. (1989) Demarginalizing the Intersection of Race and Sex: A Black Feminist Critique of Antidiscrimination Doctrine, Feminist Theory, and Antiracist Politics. University of Chicago Legal Forum, 139: 139-167.

Daly M. (2011) What Adult Worker Model? A Critical Look at Recent Social Policy Reform in Europe from a Gender and Family Perspective. Social Politics, 18 (1): 123.

Fowler B. (2003) Reading Pierre Bourdieu's Masculine Domination: Notes towards an Intersectional Analysis of Gender, Culture and Class. Cultural Studies, 17 (3-4):468-494.

Giritli Nygren, K. Fahlgren, S. \& Johansson, A. (2016) Normalization Meets Governmentality: Gender Equality Reassembled. L. Martinsson, G. Griffin, K.Giritli Nygren (eds.) Challenging the Myth of Gender Equality in Sweden. London: Policy Press: 49-68.

Hancock A. M. (2007) When Multiplication doesn’t Equal Quick Addition: Examining Intersectionality as a Research Paradigm. Perspectives on Politics, 5 (1):63-79.

Harnois C. E. (2009) Imagining a 'Feminist Revolution'. Can Multiracial Feminism Revolutionize Quantitative Social Science Research? M. T. Berger, K. Guidroz (eds.) The Intersectional Approach. Transforming the Academy through Race, Class, and Gender. Chapel Hill, NC: University of North Carolina Press: 157-172.

Harnois C. E. (2013) Feminist Measures in Survey Research. Thousand Oaks, CA: Sage.

Harnois C.E., Ifatunji M. (2011) Gendered Measures, Gendered Models: Toward an Intersectional Analysis of Interpersonal Racial Discrimination. Ethnic and Racial Studies, 34 (6): 1006-1028.

Larsson B., Letell M., Thörn H. (eds.) (2012) Transformations of the Swedish Welfare State: From Social Engineering to Governance? Basingstoke: Palgrave Macmillan.

Le Roux B., Rouanet H. (2010) Multiple Correspondence Analysis. Thousand Oaks, CA: Sage.

Lee N., Garlough C.L., Friedland L.A., Shah D. V. (2012) Gender and Generation in the Social Positioning of Taste. Annals of the American Academy of Political and Social Science, 644 (1): 134-146.

Lewis J. (2005) The Changing Context for the Obligation to Care and to Earn. M. Maclean (ed.) Family Law and Family Values. Oxford: Hart Publishing: 59-80.

Lutz H., Herrera Vivar M. T., Supik L. (2011) Framing Intersectionality: Debates on a Multifaceted Concept in Gender Studies. Farnham: Ashgate. 
Lykke N. (2011) Intersectional Analysis: Black Box or Useful Critical Feminist Thinking Technology? H. Lutz, M. T. Herrera Vivar, L. Supik (eds.) Framing Intersectionality: Debates on a Multi-faceted Concept in Gender Studies. Farnham: Ashgate:207-220.

Martinsson L., Griffin G., Giritli Nygren K. (2016) Challenging the Myth of Gender Equality in Sweden. London: Policy Press.

McCall L. (2005) The Complexity of Intersectionality. Signs, 30 (3): 1771-1800.

Nakano Glenn E. N. (2002) Unequal Freedom: How Race and Gender Shaped American Citizenship and Labor. Cambridge, MA: Harvard University Press.

Olofsson, A., Öhman, S. (2007) Views of Risk in Sweden: Global Fatalism and Local Control - An Empirical Investigation of Ulrich Beck's Theory of New Risks. Journal of Risk Research, 10 (2): 177-196.

Penner A. M., Saperstein A. (2013) Engendering Racial Perceptions: An Intersectional Analysis of how Social Status Shapes Race. Gender \& Society, 27 (3):319-344.

Scott J. (2010) Quantitative Methods and Gender Inequalities. International Journal of Social Research Methodology, 13 (3):223-236.

Sprauge J. (2005) Feminist Methodologies for Critical Researchers: Bridging Differences. Walnut Creek, CA: AltaMira.

Tatli A., Özbilgin M.F. (2012) An Emic Approach to Intersectional Study of Diversity at Work: A Bourdieuan Framing. International Journal of Management Reviews, 14(2): 180-200.

Veenstra G. (2009) Racialized Identity and Health in Canada: Results from a Nationally Representative Survey. Social Science and Medicine, (69): 538-542.

Veenstra G. (2011) Race, Gender and Class and Sexual Orientation: Intersecting Axes of Inequality and Self-rated Health in Canada. International Journal for Equity in Health, 10 (1), DOI: 10.1186/1475-9276-10-3.

Walby S., Armstrong J., Strid S. (2012) Intersectionality: Multiple Inequalities in Social Theory. Sociology, 46 (2):224-240. 